\title{
Regulações territoriais e expansão urbana informal: é possível preservar e incluir?
}

\author{
FREITAS, Clarissa F. Sampaio ${ }^{1}$ \\ 1PPGAU+D Programa de Pós-graduação em Arquitetura Urbanismo e Design, \\ Universidade Federal do Ceará, Brasil. clarissa@arquitetura.ufc.br
}

\section{Resumo}

A ascensão do objetivo da proteção ambiental interfere sobremaneira no modelo de urbanização das metrópoles brasileiras, seja na direção da universalização do acesso ao bem comum ou da privatização do mesmo. Este artigo discute uma formulação discursiva muito influente entre gestores urbanos e tomadores de decisão, que se apropria do objetivo da proteção ambiental para legitimar regulações territoriais restritivas, com efeitos socialmente perversos. $O$ artigo discute a urbanização da Área de Proteção Ambiental do Rio São Bartolomeu, no Distrito Federal, para relacionar as pautas de proteção ambiental e de inclusão urbana, considerando a crescente magnitude da urbanização informal. Adota métodos de sobreposição espacial de dados secundários e pesquisa documental para realizar uma análise histórico-geográfica do processo de expansão urbana de Brasília, e avaliar os efeitos e a pertinência das restrições legais impostas em nome da proteção ambiental. Tendo como base as informações levantadas, o artigo sugere que a problemática ambiental urbana atual é antes de tudo uma questão política pelo acesso ao espaço urbano e suas benfeitorias. Mas deixa claro também que as opções morfológicas - padrões de urbanização - são cruciais para facultar um acesso à cidade mais democrático.

Palavras-Chave: Regulações territoriais; Proteção Ambiental; Assentamentos Informais; Expansão Urbana.

\section{Abstract}

The rising legitimacy of environmental protection goal affect the urban development process of Brazilian metropolises: be it by promoting universal access to public goods, be it by hindering it. This article examines a specific discursive formulation, with great purchase among policy-makers, that has been using the environmental protection goal to legitimize restrictive urban regulations with socially perverse effects. It analyses the urbanization process within the limits of the Environmental Protection Area (APA) of São Bartolomeu River, located in Brazilian Federal District, in order to the relate the two agendas: environmental protection and the urban inclusion, in a context of increasing informal development. Uses mixed-methods research that combines spatial overlay of secondary data and document analysis to produce an historicalgeographical account of the urban expansion of Brasilia toward the APA, evaluating the effects and the pertinence of legal restrictions imposed in the name of environmental protection. Drawing from the data collected, the article claims that the current urban environmental question can be understood as a political struggle for access to urban land and investments. Yet, the article also reveals that the morphological choices - urban standards and building codes - are crucial to allow a more democratic access to the city.

Key-Words: Land Use Regulations; Environmental Protection; Informal Settlements; Urban Expansion. 


\section{Introdução}

Já faz algum tempo que a questão dos impactos da urbanização sobre o quadro natural saiu do seleto grupo de especialistas no assunto e passou a ocupar as páginas dos jornais diários de grande circulação. Invariavelmente o "crescimento urbano desordenado" é colocado como a principal causa do problema da degradação ambiental. Esta formulação discursiva normalmente se desenvolve invocando o aspecto da falta de controle urbanístico, da crônica desobediência às normas de uso e ocupação do solo e, em última instância, da falta de consciência ecológica. Para o senso comum, estes aspectos explicam as causas da ocupação de áreas sensíveis ocasionando a degradação ambiental.

Entretanto, em uma formulação menos simplista da questão, a literatura urbana brasileira tem destacado que os assentamentos informais de baixa renda se devem, em grande medida, à reduzida oferta de terrenos urbanizados a preços acessíveis à maior parte da população (Fernandes, 2009). Ao considerar este fator, autores como Rolnik (2001) argumentam que o foco na desordem urbana ajuda a esconder a principal raiz da insustentabilidade ambiental de nossas cidades: o processo desigual de produção do espaço urbano, que restringe a ocupação urbana legalizada a uma minoria que pode pagar o alto preço desta mercadoria. A lei de mercado tem sido protegida pela ordem urbanística vigente na maior parte das cidades brasileiras. Estudiosos do espaço urbano argumentam que, ao permitir que a minoria se aproprie da mais-valia fundiária, a terra urbanizada e legalizada torna-se uma mercadoria de luxo (Maricato, 2001; Campos Filho, 1999).

Neste contexto, torna-se importante evidenciar a intricada relação entre uma ordem urbanística excludente e o fenômeno da informalidade urbana. Para Moretti (1997), Martins (2006) e Mukhija, and Loukaitou-Sideris, (2014), o processo de ocupação informal $^{1}$ pela baixa renda é alimentado pelo estabelecimento de parâmetros de uso e ocupação do solo restritivos, que contribuem para o alto preço da terra legalmente urbanizada. Tendo em vista que a informalidade tende a concentrar-se em áreas de maior sensibilidade ambiental desprezadas pelo

\footnotetext{
Adota-se aqui o termo informal, seguindo autores como Calderon (1998) e Mukhija, and Loukaitou-Sideris, (2014), que se referem atividade que ocorrem a revelia das regulações do Estado, não apresentando proteção das regras institucionais vigentes. $\mathrm{O}$ termo possui certa sobreposição ao
}

mercado imobiliário formal (Freitas, 2014; Martins 2006; Maricato 2001; Torres, 1997), percebe-se uma relação direta entre o mercado imobiliário, a ordem urbanística vigente, e a degradação ambiental urbana. Assim, ao considerarmos o processo de produção do espaço urbano brasileiro, seria a ordem urbana vigente - e não a desordem - que tem dificultado a implantação do projeto de sustentabilidade socioambiental. Considerando que na maioria esmagadora dos casos a ordem urbanística vigente atende aos interesses do mercado imobiliário, invocar o poder de polícia do Estado para impô-la significa, em muitos casos, limitar o acesso da população carente à cidade.

Como mudar a ordem urbanística vigente? Quais as forças sociais e os grupos políticos capazes de influenciar tal ordem? Historicamente o movimento de moradia aglutinava a principal oposição a uma tendência de exclusão social do planejamento urbano. No entanto, no cenário político atual, são frequentes casos em que o movimento de moradia parece contentar-se ao gradativo reconhecimento dos direitos à ocupação, perpetuando um processo de clientelismo político urbano. Esta postura em nada contribui para a construção de cidades sustentáveis do ponto de vista social e ambiental. Por outro lado, nas últimas décadas, o movimento ambientalista tem ganhado uma legitimidade ocupando um espaço privilegiado no debate da gestão da cidade. Não seria difícil aceitar o argumento de que, no combate a um modelo de planejamento urbano que apoia a obtenção de lucro privado em detrimento de objetivos coletivos, o setor ambientalista tem obtido mais vitórias que o movimento de moradia. Apesar do sucesso do movimento ambientalista ainda ser muito tímido, ele pode ser visto, por exemplo, no avanço da incidência da legislação ambiental brasileira sobre os territórios urbanos.

Infelizmente tal avanço da pauta ambiental não tem incentivado modelos de ocupação urbana que atenda ambos os objetivos. Um recente artigo sobre o tratamento da questão ambiental nos Planos Diretores Municipais pós Estatuto da Cidade (Araujo et al, 2011) ilustra este argumento ao afirmar que

conceito de Ilegal, irregular ou clandestino, embora não possam ser considerados sinônimos. Optou-se por preservar a nomenclatura de "loteamentos ilegais" quando se trata de referência direta a documentos oficiais que assim se referem aos mesmos. 
"em geral, os Planos Diretores analisados tratam a questão do meio ambiente sob o prisma apenas da agenda verde, ou seja, da arborização urbana e da preservação dos espaços livres e Unidades de Conservação". Como se lotear, construir, e ocupar o espaço urbano fossem atividades "não ambientais", e que somente a ação de não-ocupar e manter intocado fosse afeito ao campo ambiental. Em última instância, tal ponto de vista acaba por induzir regulações que, em nome da proteção dos ecossistemas, buscam evitar a cidade a qualquer custo. Com base em uma tradição iluminista de oposição entre sociedade (cidade) e natureza, a legislação ambiental quando aplicada ao território urbano costuma induzir um modelo de ocupação do território inacessível para grande parte da população urbana.

Potencializando esse antagonismo entre cidade e natureza, a ocupação de áreas frágeis pela população de baixa renda gera uma percepção de que a inclusão urbana só seria possível através da regularização fundiária. E esta, quando se trata de assentamentos em áreas sensíveis, será necessariamente uma perda do ponto de vista da proteção dos ecossistemas urbanos ${ }^{2}$. Contradizendo a percepção dominante no senso comum, este artigo aponta para a possibilidade de planejar o território urbano de forma a atender, tanto os setores sociais envolvidos com o direito à moradia, como aqueles ligados à proteção ambiental. Pretende-se aqui destacar uma relação de complementaridade entre a proteção ambiental e a inclusão urbana, através do estudo de uma APA localizada em uma zona de expansão urbana de Brasília.

O estudo ilustra um processo já diagnosticado pela literatura urbana brasileira (Martins, 2006; Maricato, 2001), de que a ausência de preocupação com a oferta de terra urbanizada a preços acessíveis à população de baixa renda possui custos sociais e ambientais. Tais custos são evidentes no processo que tem sido denominado de Desigualdades Ambientais (Torres, 1997). Desigualdade Ambiental refere-se ao fato de que grupos sociais vulneráveis estão desproporcionalmente expostos a riscos ambientais associados a carências no processo de

\footnotetext{
${ }^{2}$ Para um caso representativo desta formulação discursiva que usa a proteção ambiental para justificar a remoção de assentamentos informais ver Compans (2007).
}

urbanização e a sensibilidade do sitio urbano, como enchentes e desmoronamentos, devido a fatores estruturais no processo de formação de nossas cidades. Partindo desta premissa adotamos a seguinte questão central da pesquisa: Qual o papel da ascensão do objetivo da proteção ambiental no processo de exclusão socioespacial, informalidade urbana e degradação ambiental que caracteriza as áreas de expansão urbana das cidades brasileiras? Baseado nesta breve revisão bibliográfica, formulamos a hipótese de que as regulações ambientais têm alimentado a tendência de exclusão sócio-espacial, pois o objetivo da proteção ambiental tem sido usado como desculpa para justificar regras com efeitos excludentes. Tal hipótese será testada a partir da análise do processo de urbanização da Área de Proteção Ambiental (APA) do rio São Bartolomeu, que abrange uma área de expansão urbana de Brasília no Distrito Federal. Em última análise, o caso estudado nos permitirá refletir sobre a viabilidade de novos modelos de ocupação voltados para a qualificação do ambiente urbano que superem a reprodução dos modelos tradicionais.

Trata-se de uma análise histórico-espacial que sistematiza a evolução das regulações urbanas e ambientais da APA escolhida, relacionando -a com dinâmica ambiental e urbana desde a criação da APA no inicio da década de 1980. Apoia-se em um Sistema de Informações Geográficas composto por variáveis urbanísticas e socioeconômicas (renda, localização/status dos assentamentos e densidades); variáveis ambientais (nível de sensibilidade do quadro natural e sua adequação para a urbanização); e a dimensão legal (sucessivas regras de ocupação territorial). A sobreposição espacial destas 3 dimensões de analise (urbanização, quadro natural e regulação), permitida pelos softwares de Geoprocessamento, nos permitiu uma compreensão aprofundada dos efeitos das regulações sobre o processo de ocupação territorial no período. Tal compreensão foi complementada pela análise dos documentos que informam as alterações nas regulações urbanas e ambientais, o que nos permitiu avaliar o papel das preocupações ambientais no contexto de disputa pela terra urbanizada entre os diversos agentes produtores do espaço. A escolha do 
caso se justifica por se tratar de um território cuja urbanização recente se deu sob a vigência de uma série de limitações a ocupação urbana de ordem ambiental, e pela disponibilidade de informações produzidas por diversos órgãos, como o IBGE, os órgãos locais de planejamento urbano do Distrito Federal e órgãos federais de proteção ambiental.

$\mathrm{O}$ artigo está estruturado da seguinte maneira. $\mathrm{O}$ Item 02 apresenta a dinâmica urbana no território estudado tomando como ponto de partida o inicio da década de 1980, quando se inicia as preocupações com o modelo de ocupação territorial; o item 03 apresenta a sucessivas alterações nas regulações territoriais, relacionando-as com o estagio de urbanização de cada período, buscando ainda ressaltar o papel do discurso de proteção ambiental para legitimar as restrições à urbanização. O item 04 avalia a pertinência das restrições impostas ao apresentar a dinâmica do quadro natural. Tendo como base as informações levantadas o artigo sugere que a problemática ambiental urbana atual é antes de tudo uma questão política pelo acesso ao espaço urbano e suas benfeitorias. Mas deixa claro também que as opções morfológicas - padrões de urbanização - são cruciais para facultar um acesso à cidade mais democrático.

\section{Dinâmica Urbana da APA do rio São Bartolomeu}

A bacia do rio São Bartolomeu possui uma área de drenagem de cerca de $1500 \mathrm{~km} 2$, correspondendo a 23\% do território do Distrito Federal. Localiza-se imediatamente a leste da bacia do Lago Paranoá, que abriga o Plano Piloto de Brasília (ver Figura 1).

Figura 1: APA do Rio São Bartolomeu no contexto do Distrito Federal.

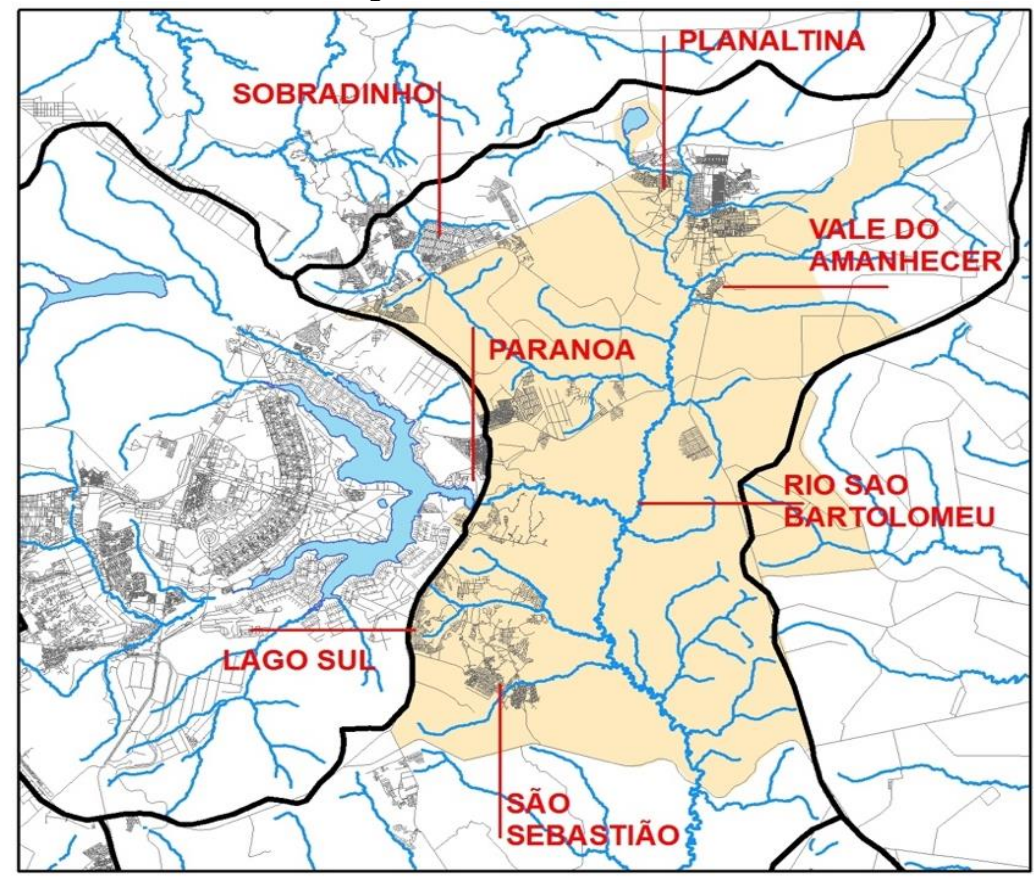

Fonte: Freitas 2009
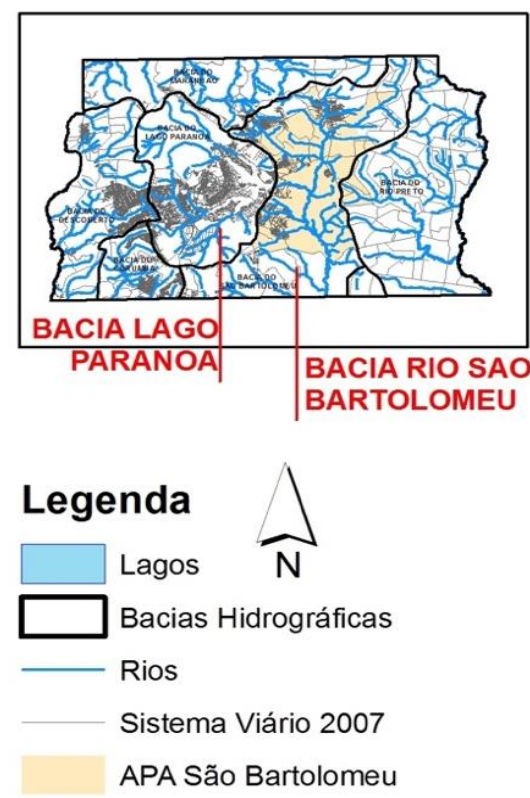

$10.0005 .000 \quad 0$

10.000 Meters
É sabido que antes da construção do Plano Piloto, inaugurado em 1960, o governo federal iniciou um processo de desapropriação de terras das fazendas localizadas no interior dos limites do recém-criado Distrito Federal. A transferência da propriedade da terra para o poder público foi iniciada pela Bacia do Lago Paranoá, sítio escolhido para implantação da capital. A intenção inicial era a irradiação do processo de desapropriação para todo o Distrito Federal. No entanto, este processo não foi concluído, e grande parte da área localizada a leste da Bacia do
Lago Paranoá permaneceu de propriedade particular até os dias atuais. Esta área coincide com a Bacia do Rio São Bartolomeu, onde seria implantada uma das duas primeiras APAs do Brasil em 1983.

O Rio São Bartolomeu é o maior rio do Distrito Federal e corta o DF no sentido norte-sul. Desde os primeiros documentos de planejamento urbano da capital federal, na década de 1970, ele foi identificado como a fonte de água potável mais apropriada para abastecer a população que crescia a 
taxas bastante altas nesse período. Devido ao projeto de construção de um reservatório para abastecimento populacional no leito do Rio São Bartolomeu, os primeiros planos diretores do DF não recomendavam a expansão urbana na direção leste. Assim o controle da urbanização desta área justificase inicialmente pela garantia da manutenção da qualidade da água no reservatório a ser construído. Em 1983, com o aumento da pressão por novas áreas de expansão próximas ao Plano Piloto, o instrumento legal escolhido para efetivar a diretriz de não ocupação da bacia do São Bartolomeu foi um recém-criado tipo de Unidade de Conservação Ambiental denominado de Área de Proteção Ambiental (APA), que não requeria desapropriação de terras, ao contrário dos outros tipos de Unidades de Conservação existentes na época (Brasil, 1988).

A despeito de diversas tentativas de controle do processo de urbanização do território da APA, sua população aumentou $18 \%$ ao ano no período compreendido entre 1988 e 2000. O crescimento populacional desta área periférica acima da média do DF representa uma tendência de espraiamento urbano já detectada pela literatura em outras metrópoles brasileiras. Ela é caracterizada, em sua maioria, pela criação de uma periferia de assentamentos de baixa renda com pouca infraestrutura. Mas essa periferia não é homogeneamente precária. Em geral existe um setor da cidade que responde à demanda por moradia da classe média alta, em lotes maiores e lugares mais afastados das zonas de concentração de emprego (em Belo Horizonte ver Costa et al, 2006). No DF a bacia do São Bartolomeu parece abrigar esta dupla tendência de dispersão urbana, tanto das classes média e alta, e como das classes populares.

Na época de criação da APA, em 1983, não existiam assentamentos urbanos significativos dentro dos limites estabelecidos. Entretanto a tendência de ocupação urbana já estava sendo detectada. Os primeiros estudos sobre o território identificaram, em 1988, 22 loteamentos ilegais e duas pequenas "vilas": O Vale do Amanhecer, na porção nordeste da APA com 5.000 habitantes estimados, e a Vila de São Sebastião, na porção sudeste com uma população

${ }^{3}$ Cidade-satélite é a divisão administrativa do Distrito Federal tendo em vista que o mesmo é uma unidade da federação que não pode ser subdividida em municípios. O governo do Distrito Federal acumula as estimada em 1.500 habitantes (Brasil, 1988).

$\mathrm{Na}$ mesma época existiam três assentamentos formais nos limites externos da APA: as cidades de Planaltina, Sobradinho e o Lago Sul. Esta última é um bairro dormitório da classe alta local. Foi projetada por Lucio Costa, que previu lotes grandes e ruas sem saída e generosos espaços verdes públicos. A cidade de Planaltina é bem mais antiga e data de meados do século XIX, ou seja, sua fundação é preexistente à construção do Plano Piloto. Com a vinda da capital federal, em 1960, Planaltina transformou-se em uma cidade-satélite de baixa renda, devido a sua localização distante do centro gerador de oportunidades de trabalho. Atrai uma população de baixa renda, que não pôde pagar por terras mais bem localizadas. Atualmente a cidade é um dos maiores polos concentradores de assentamentos informais de baixa renda no DF. A cidade de Sobradinho está localizada entre Planaltina e o Plano Piloto. Foi uma das três primeiras cidades-satélites construídas ainda na década de 1960, para abrigar a classe trabalhadora fora dos limites do Plano Piloto. Atualmente sua população possui índices socioeconômicos muito próximos à média do $\mathrm{DF}$, e a qualidades dos serviços urbanos também é satisfatória.

Outro assentamento que se localiza muito próximo ao limite da APA do Rio São Bartolomeu, porém não considerado uma cidade-satélite ${ }^{3}$ - quando foi criada a APA - é a vila do Paranoá. Formada por acampamento de trabalhadores da construção civil localiza-se próxima à barragem do lago Paranoá, e ao limite oeste da APA.

$\mathrm{O}$ incremento populacional dos assentamentos localizados dentro dos limites da APA em 1983, e o surgimento de outros núcleos populacionais não é tão natural ou incontrolável como o discurso público tende a descrever. Este processo de explosão populacional largamente informal, que comumente é descrito como caótico e de difícil controle, possui relação bastante direta com os investimentos públicos realizados na área, como a expansão da rede viária e das redes de serviços urbanos para abastecer as novas cidades-satélites instaladas pelo poder

funções dos estados e dos municípios sendo, portanto ele o responsável pela política urbana do território do DF como um todo, e não os administradores das cidades-satélites, cargos não eletivos. 
público na região.

De certo modo, pode-se afirmar que o incremento populacional deste território acontece com a anuência do governo local. Isto se dá porque, apesar dos assentamentos informais terem sido construídos por agentes privados, os investimentos públicos instalados naquela direção tiveram um papel fundamental em viabilizar a urbanização que ocorre após a criação da APA. Talvez o melhor exemplo de investimento público com tais efeitos é a terceira ponte sobre o Lago Paranoá. Inaugurada em 2003, essa obra viária transforma-se em um importante vetor de crescimento da cidade na direção da área protegida.

Entretanto, bem antes da inauguração da 3a ponte, outros investimentos públicos canalizaram a mancha urbana de Brasília nesta direção, e induziram a urbanização informal. A construção das cidades-satélites de Paranoá e São Sebastião demandaram a expansão das redes de infraestrutura na direção da APA, viabilizando os assentamentos informais nas suas bordas. A cidade do Paranoá foi construída em 1989 numa área próxima ao limite ocidental da APA e tinha como objetivo o reassentamento de uma população que morava na vila do Paranoá. Ela vem a se expandir informalmente em 2005 com a invasão da área de proteção de mananciais (APM) do Itapoã. Em 2010, o Paranoá conta com uma população de 53 mil habitantes sendo que destes, 35 mil são moradores da invasão do Itapoã (IBGE 2010).

A segunda cidade-satélite, São Sebastião, foi construída em 1991 numa área localizada no coração da porção sudoeste da APA. Pretendia reassentar os 7.620 habitantes que viviam em uma área de risco nas margens de dois tributários do rio São Sebastião, mas foi projetada para uma população total de 35.000 habitantes. Em 2010, de acordo com os dados do censo IBGE, sua população já ultrapassa 50.000 moradores graças a dois grandes assentamentos informais de baixa renda na periferia da cidade de iniciativa estatal (ver também, Freitas e Gomes, 2009). Contraditoriamente, São Sebastião foi construída em uma área que estava prevista para ser inundada pelo reservatório projetado em 1988.

Ao acompanhar a dinâmica urbana do território delimitado como APA desde 1983 percebe-se uma clara disjunção entre o discurso oficial de limitar seu crescimento urbano e o padrão de urbanização e investimentos públicos realizados. A crescente legitimidade das políticas de regularização fundiária no cenário nacional e internacional permitiu que o poder público local fosse aos poucos sinalizando que todos os assentamentos informais seriam regularizados, sem considerar o nível de renda de seus moradores (Batella, 2003). De acordo com Batella, sucessivas legislações distritais foram estendendo a data limite que estabelecia quem tinha o direito a ter sua propriedade regularizada. Esta postura do poder público local acabou por alimentar o cenário de incremento populacional descontrolado apresentado.

Como explicar esta disjunção entre o objetivo da política publica de ordenamento territorial e a prática cotidiana da gestão urbana? Embora o adensamento do território da APA pareça não fazer sentido do ponto de vista do interesse coletivo, podem-se identificar dois grupos de agentes produtores do espaço urbano que possuem interesse neste processo.

O primeiro grupo é formado pelos proprietários e empreendedores responsáveis pela urbanização informal das terras particulares remanescentes no interior da APA. Estes obtiveram ganhos especulativos com a transformação da zona rural em cidades providas de serviços urbanos, ao menos parcialmente. Dentre este grupo, que chamaremos genericamente de proprietários, devemos incluir também a agência gerenciadora das terras públicas do Distrito Federal (TERRACAP), cuja terra aumentou de preço devido à expansão das redes de infraestrutura e serviços urbanos na direção das cidades-satélites destinadas a abrigar a população de baixa renda, descrita anteriormente.

O segundo grupo de agentes que obtiveram vantagens com esse processo de urbanização aparentemente desordenado são os agentes políticos. Estes obtiveram ganhos eleitorais ao anunciar a regularização e/ou urbanização, sempre em nome do “direito à cidade". Entretanto, muitas das iniciativas estatais de regularização na APA não seguem os princípios constitucionais do direito à cidade, por beneficiarem lotes vazios ou lotes ocupados pelas classes média e alta com valores de mercado bastante acima da faixa de baixa-renda. Em muitos dos 
loteamentos que estão sendo regularizados, o tamanho médio dos lotes ultrapassa 500m2.

Tal constatação permite identificar pelo menos dois processos de produção informal do espaço diferenciados: o primeiro atende a demanda da população de baixa renda, com alta densidade e rápida velocidade de ocupação os assentamentos produzidos dessa forma localizam-se na periferia das cidades-satélites de Paranoá, São Sebastião e Planaltina. O segundo processo atende a população de alta e média renda, localizados em sua maioria na periferia do Lago Sul, particularmente na sub-bacia do ribeirão Taboca, se estendendo na direção norte.

Tabela 1: Loteamentos ilegais por nível de renda

\begin{tabular}{|c|c|c|}
\hline & $\begin{array}{l}\text { Assentamentos } \\
\text { de baixa renda } \\
\text { (0 a } 5 \mathrm{sm})\end{array}$ & $\begin{array}{l}\text { Assentamentos } \\
\text { de renda media } \\
\text { e alta }\end{array}$ \\
\hline $\begin{array}{l}\text { Lotes } \\
\text { ocupados }\end{array}$ & 38.367 & 9.848 \\
\hline $\begin{array}{l}\text { Lotes } \\
\text { previstos }\end{array}$ & 41.337 & 22.626 \\
\hline $\begin{array}{l}\text { Lotes } \\
\text { vagos }\end{array}$ & 2.758 & 10.460 \\
\hline $\begin{array}{l}\% \text { de lotes } \\
\text { vagos }\end{array}$ & $7 \%$ & $46 \%$ \\
\hline População & 160.440 & 41.113 \\
\hline
\end{tabular}

Fonte: DISTRITO FEDERAL; SEDUH; SUPAR (2006)

Figura 2: Loteamentos ilegais por nível de renda

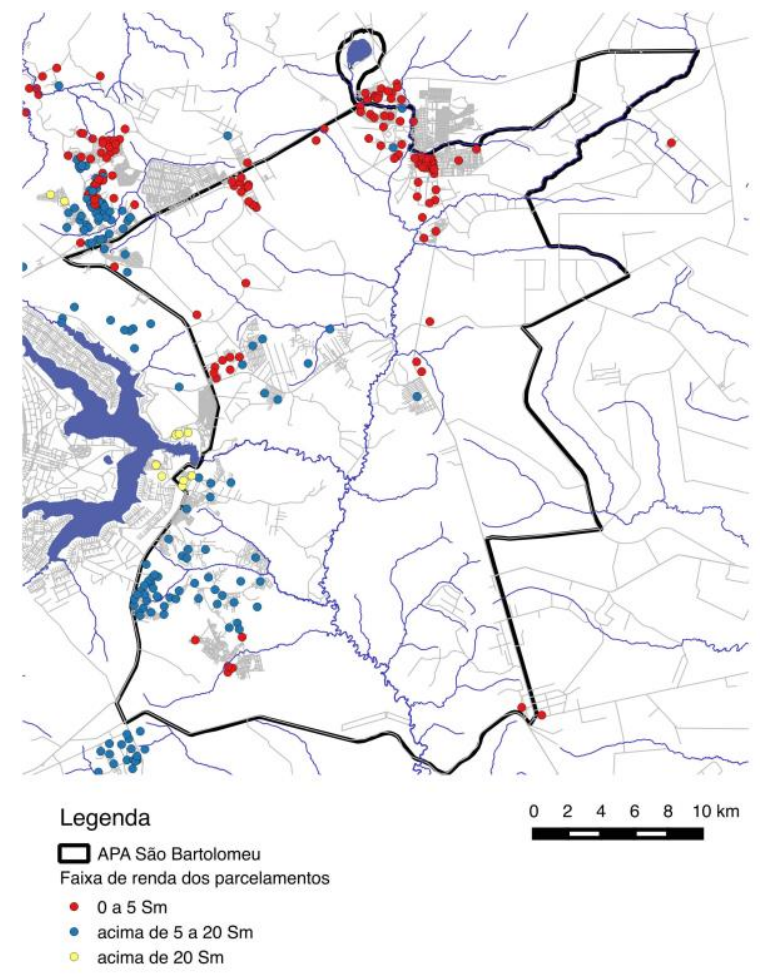

Fonte: DISTRITO FEDERAL; SEDUH; SUPAR (2006)
Tais assentamentos apresentam grande quantidade de lotes vazios e velocidade de ocupação bastante inferior ao processo de urbanização da baixa renda, indicando, portanto, uma menor demanda por moradia. Além disso, os loteamentos destinados às classes média e alta consomem muito mais terra devido à baixa densidade, ao maior tamanho de lote, e à desconexão entre os empreendimentos (ver Figura 2 e Tabela 1).

\section{Regulações Urbanas e Ambientais da APA do rio São Bartolomeu}

As regulações de uso e ocupação na APA apresentam três momentos de mudanças desde sua criação em 1983. O primeiro momento foi em 1988, ano da aprovação do primeiro zoneamento ambiental; o segundo, em 1996, quando foi alterada esta primeira regulação através da aprovação de uma lei que ficou conhecida como o rezoneamento; e o terceiro momento ocorre em março 2009, quando se dá a aprovação do atual plano de ordenamento territorial (PDOT equivalente ao Plano Diretor) que altera disposições existentes no rezoneamento em vigor desde 1996. A Figura 4, apresenta uma cronologia destas regulações, relacionando-as com o processo de urbanização e ocupação da APA.

\subsection{O primeiro zoneamento}

Em 1988, tendo como base um estudo do quadro biofísico do polígono da APA, e assumindo a construção de um reservatório na cota 865 do leito principal do Rio São Bartolomeu, o primeiro zoneamento ambiental é aprovado proibindo qualquer tipo de uso urbano. Apesar de ter sido legalmente aprovado na forma de uma lei federal, este zoneamento não obteve êxito em conter o crescimento da urbanização de Brasília para o interior da APA. Em 1988, a APA era gerenciada pelo governo federal, e exatamente neste ano, o governo local do Distrito Federal foi criado. Antes de 1988, todas as decisões relativas à gestão urbana do território do DF estavam a cargo do governo federal. No processo decisório a respeito da urbanização do DF, o recém-criado governo local desconsiderou as diretrizes legais do zoneamento ambiental. $\mathrm{O}$ fato de que no período de 3 anos após a 
aprovação do zoneamento, o governo local constrói duas cidades satélites dentro ou na área de influencia do polígono delimitado como APA revela o conflito entre as políticas urbanas $\mathrm{e}$ ambientais, assim com a desconexão entre as diretrizes locais e federais.

Figura 3: Cronologia do desenvolvimento urbano na APA do Rio São Bartolomeu

$\mathbf{1 9 8 3}$ - Criação da APA
1984 - 90 loteamentos ilegais mapeados
1988 - Estimativa populacional de 20 mil hab.
$\mathbf{1 9 8 8}$ - Primeiro Zoneamento Ambiental
1989 - Criação da Cidade Satélite do Paranoá
1991 - Criação da Cidade Satélite de São Sebastião
1994 - 105 loteamentos ilegais mapeados
$\mathbf{1 9 9 6}$ - Segundo Zoneamento Ambiental
$\mathbf{1 9 9 7}$ - Aprovação do PDOT 1997
2000 - Estimativa Populacional de 158 mil
habitantes
2003 - Inauguração da Ponte JK
2004 - Invasão do Itapoã
2006 - 146 loteamentos ilegais mapeados
$\mathbf{2 0 0 9}$ - Terceiro Zoneamento: PDOT 2009
2010 - Estimativa Populacional de 213 mil hab.

Fonte: elaboração do autor, a partir de dados secundários.

\subsection{0 segundo zoneamento}

Em 1996 este primeiro zoneamento ambiental foi revisto através da aprovação do rezoneamento ambiental da APA do São Bartolomeu (lei 1.149 de 11 de julho de 1996). Esta nova regulação destinou cerca de $5 \%$ do território da APA para uso urbano. A adoção desta nova regulação significava o abandono do projeto de construção de um único lago na cota 865 . Em seu lugar, o rezoneamento baseia-se em um segundo projeto de captação da água do rio que prevê a construção de dois reservatórios menores. Um primeiro na mesma cota 865 , mas com uma barragem de menor altura, e o segunda na confluência do Rio São Bartolomeu com o Rio Paranoá, que recebe as águas do Lago Paranoá, famoso cartão postal do Plano Piloto de Brasília. Tais reservatórios resultam em uma área de espelho d'água bem menor que o primeiro, permitindo destinar $5 \%$ do território para urbanização.

A revisão da regulação original tinha como objetivo a racionalização do uso do solo no sentido de não comprometer a possibilidade de utilização da água como recurso natural para abastecimento, reconhecendo, no entanto, a existência de pressões por ocupação urbana do território. Em outras palavras, o alto custo social e político da reversão da urbanização em todo o território da APA justificou a primeira alteração na proposta inicial de zoneamento, e a formulação de um projeto menos ambicioso de captação da água do lago. Percebe-se também nos documentos oficiais que a preocupação sanitária, e com viés utilitarista, vai aos poucos dando lugar a um discurso preservacionista. $\mathrm{O}$ próprio documento técnico do rezoneamento revela em algumas passagens que a região da APA possui características físicas singulares que justificam a sua proteção mesmo em um cenário de não construção da barragem.

A maior parte da mancha urbanizável definida no rezoneamento de 1996 localiza-se prioritariamente nas áreas de maior altitude próximas aos bairros do Lago Sul e Lago Norte. Além desta área o rezoneamento classifica como passível de urbanização outras duas áreas descontínuas, sendo uma delas próxima da cidade de Planaltina e a outra na periferia de São Sebastião (ver Figura 5). Tratam-se de espaços com menores vantagens locacionais e, portanto, financeiramente mais acessíveis à população de baixa renda se comparada à mancha urbanizável principal.

Ao analisar a proposta de rezoneamento a luz das informações existentes na época, percebese que o limite urbanizável adotado não inclui todos os loteamentos existentes na época. O documento técnico que justifica a lei identifica todos os loteamentos existentes, nomeia todos aqueles passíveis de regularização, e sugere a desconstituição de todos os loteamentos que não se localizavam dentro da área permitida. Entretanto em nossa pesquisa não encontramos registros de nenhum caso em que essa medida tenha sido efetivada.

Se não houveram casos de desconstituição de loteamentos não autorizados, percebemos indícios de valorização imobiliária dos loteamentos localizados na mancha urbanizável, particularmente daqueles na porção de maior altitude e próxima ao Lago Sul e ao Lago Norte no limite oeste do polígono da APA. 
Posteriormente, em 1997, viria a ser aprovado um novo o plano de ordenamento territorial (PDOT-97). O documento técnico deste plano descreve o rezoneamento como "o documento que abre caminhos para a regularização dos loteamentos irregulares", o que revela que já em 1997 havia uma grande legitimidade política para ações de regularização. Este plano incorporou o polígono urbanizável definido no segundo zoneamento dentro da categoria "Zona de Urbana de Uso Controlada". Definida como "zona de uso predominantemente habitacional de baixa densidade, sujeita a critérios específicos de ocupação, no qual se desestimulará a expansão do uso urbano em razão, principalmente das restrições ambientais" (Distrito Federal, 1997), o plano adota a tipologia urbana sugerida pelo estudo do rezoneamento que propõe baixa densidade (60 habitantes por hectares) indiscriminadamente em toda a zona urbanizável. Ao tomar esta medida, o plano desconsidera processos diferenciados de produção do espaço já comentados aqui. Mais diretamente, o plano desconsidera a viabilidade de efetivação da regulação urbana e ambiental tendo em vista que o padrão sugerido é financeiramente inacessível para a população de baixa renda que é a maior parte da demanda habitacional do DF. Tal dificuldade se dá, em particular, em espaços com grandes vantagens locacionais como terrenos próximos ao Lago Sul.

Após 1997, diversos fatores estimulam a não implementação dos dispositivos de controle urbanísticos sugeridos nas regulações recémaprovada. Dentre eles destaca-se a descontinuidade administrativa do governo local em 1999, que parece ter sido determinante. A despeito das razões, o fato é que os processos de parcelamento e ocupação informal não tiveram seu ritmo diminuído o que inviabilizou a construção dos reservatórios projetados em 1996.

\subsection{O terceiro zoneamento}

Em 2009 um novo plano de ordenamento territorial (PDOT-2009) é aprovado. Mais uma vez o plano é descrito como um instrumento que irá permitir a regularização fundiária e acabar com a desordem urbana. Esse tipo de propaganda suporta o argumento de que alguns agentes políticos obtêm vantagens eleitorais com o processo de descontrole urbanístico.

Diferentemente do PDOT de 1997, este plano abandona 0 projeto de construção de reservatórios para aproveitamento do Rio São Bartolomeu para abastecimento urbano. A justificativa para tanto é que o alto nível de ocupação informal e, portanto, com infraestrutura sanitária deficiente - na bacia do Rio comprometeram a possibilidade de captação da água em larga escala. Abandonado este projeto, o PDOT-2009 aumenta o limite urbanizável da APA em $500 \%$, produzindo uma mancha passível de urbanização correspondente a $25 \%$ do território da APA.

Apesar da pressão de urbanização da APA ser inegável, este aumento não se justifica se considerarmos que grande parte da mancha urbanizável definida em 1996 possui, em 2009, uma densidade ainda muito aquém daquela permitida pela regulação. Esta ociosidade no uso da terra urbanizada é particularmente presente nos espaços mais valorizados, próximos ao divisor da bacia. Contrastando com esse modelo repleto de glebas e lotes vazios nos espaços mais caros, as duas manchas descontínuas próximas às cidades-satélites de baixa-renda (São Sebastião e Planaltina e Paranoá), apresentam níveis bastante altos de crescimento populacional e densidades bastante superiores àquela estabelecida na legislação.

O PDOT 2009 classifica a área urbanizável em duas diferentes zonas descritas a seguir:

1. Zona Urbana de Uso Controlado-II (ZUUCII)

Art. 70. A Zona Urbana de Uso Controlado II é composta por áreas predominantemente habitacionais de baixa e média densidade demográfica, com enclaves de alta densidade, conforme Anexo III, Mapa 5, desta Lei Complementar, sujeitas a restrições impostas pela sua sensibilidade ambiental e pela proteção dos mananciais destinados ao abastecimento de água.

2. Zona de Contenção Urbana (ZUC) 
“Art. 76. A Zona de Contenção Urbana é composta por áreas urbanas localizadas nas fronteiras com as áreas rurais, sendo caracterizada por ocupação habitacional de densidade demográfica muito baixa, de modo a criar uma zona de amortecimento entre o uso urbano mais intenso e a Zona Rural de Uso Controlado [...].

Art. 77. A Zona de Contenção Urbana tem por objetivo assegurar a preservação e a manutenção das suas características naturais por meio do estabelecimento de parâmetros de uso e ocupação do solo restritivos.

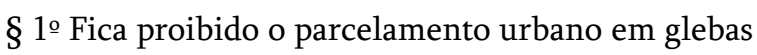
menores que 10ha (dez hectares) [...].

Art. 78. A Zona de Contenção Urbana deverá compatibilizar o uso urbano com a conservação dos recursos naturais, por meio da recuperação ambiental e da proteção dos recursos hídricos, além de conciliar o uso habitacional com o uso agrícola, de acordo com as seguintes diretrizes:

I - permitir o uso habitacional de densidade demográfica muito baixa, conforme os seguintes parâmetros de parcelamento:

a) área mínima do lote de $100.000 \mathrm{~m}^{2}$ (cem mil metros quadrados);

b) as ocupações devem ocorrer de forma condominial, respeitado o limite de 32\% (trinta e dois por cento) do total do lote do condomínio para as unidades autônomas e 68\% (sessenta e oito por cento) do total do lote do condomínio para área de uso comum;

c) as unidades autônomas devem ser projetadas, preferencialmente, de forma agrupada, respeitada a proporção máxima de 4 (quatro) unidades habitacionais por hectare;

d) área mínima da unidade autônoma de $800 \mathrm{~m}^{2}$ (oitocentos metros quadrados);

e) no máximo $8 \%$ (oito por cento) da área comum do lote do condomínio poderão ser destinados a equipamentos de lazer do condomínio (LEI COMPLEMENTAR № 803, DE 25 DE ABRIL DE 2009).
Figura 4: APA do Rio São Bartolomeu no contexto do Distrito Federal

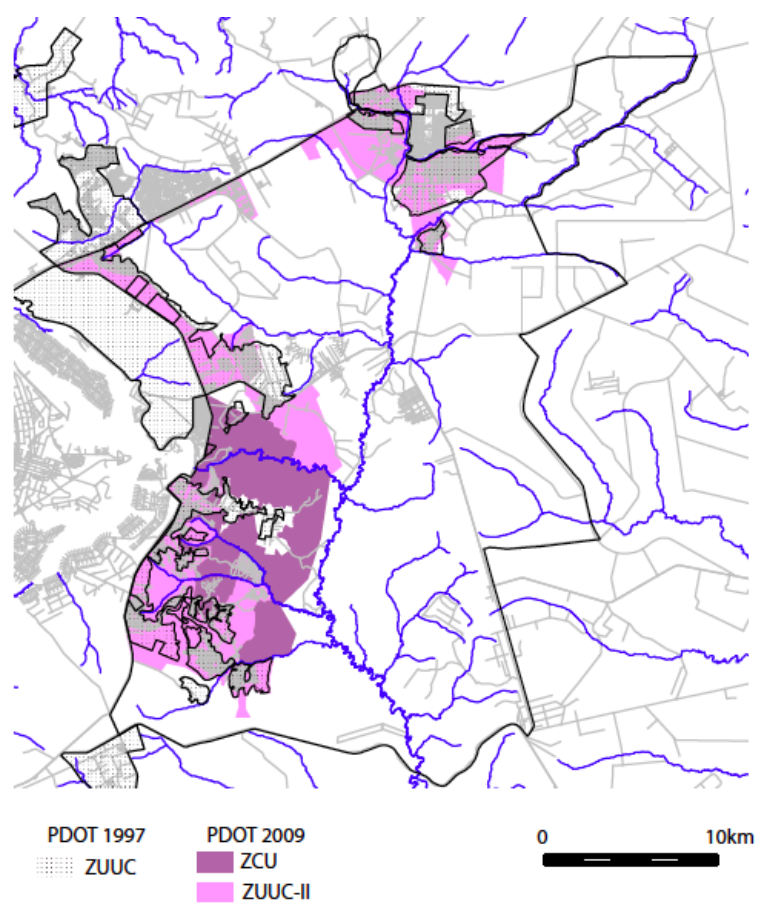

Fonte: Freitas 2009

Assim como em 1997, a questão ambiental é a principal razão para o estabelecimento de restrições de ocupação do solo na APA. A ZUUC-II adota vários limites de densidade, mas as glebas não parceladas possuem limites que variam de 50 a 150 habitantes por hectares. A Zona de Contenção urbana adota uma densidade de apenas 15 habitantes por hectares e o menor tamanho de lote permitido é de $800 \mathrm{~m}^{2}$.

Este novo plano diretor adota a mesma estratégia do plano anterior: restrição à urbanização, particularmente às altas densidades. Tal estratégia não tem se mostrado suficiente para o objetivo de contenção do avanço da urbanização. O plano não define a quantidade de espaço urbanizável de acordo com o perfil socioeconômico da demanda habitacional existente. Ele simplesmente reproduz um modelo de urbanização restritivo, apoiando-se no discurso da preservação ambiental e apelando para a fragilidade biofísica do território. Ele tampouco faz esforços para assegurar que a terra urbanizável atenda à demanda habitacional existente. Ao adotar esta estratégia, a regulação contribui para empurrar a população de baixa renda para os assentamentos informais, sem infraestrutura. 
Para piorar a situação, os assentamentos viáveis para a população de baixa renda tendem a se localizar, não apenas em áreas mais periféricas, mas também em espaços com características biofísicas pouco propícias para urbanização. 0 próximo capitulo irá desenvolver esta questão.

\section{Regulações a luz da dinâmica ambiental - Informalidade e ocupação de áreas frágeis.}

Apesar do abandono do projeto de construção de reservatórios para aproveitamento da água do Rio São Bartolomeu para abastecimento urbano, a pertinência das limitações à urbanização na APA nunca foi questionada. Isto se deve à crescente legitimidade dos objetivos da preservação ambiental na sociedade brasileira. Particularmente no contexto local do DF, o sanitarismo tem dado lugar ao ambientalismo em diversas ocasiões. Neste contexto de ascensão das preocupações ambientais, o rio São Bartolomeu é percebido como um recurso ambiental valioso, cuja bacia hidrográfica apresentaria altos níveis de sensibilidade ambiental e, portanto, inadequada para urbanização. Essa percepção muito comum entre os grupos ambientalistas locais desconsidera que esse território possui diferentes níveis de sensibilidade ambiental. Ao reconhecer tais diferenciais buscamos verificar em que medida as características do quadro natural relacionam-se com o processo de desenvolvimento urbano desigual apresentado.

Vimos que a ação do Estado - por meio de expansão das redes de infraestrutura e incentivo a loteamentos de baixa densidade - mostrou-se inadequada, ou insuficiente para conter o processo de urbanização informal e injusto. A análise do quadro natural da APA, a seguir, nos permite afirmar que a ação do Estado na gestão do território da APA teve não apenas efeitos SOCIAIS regressivos, mas também efeitos AMBIENTAIS negativos. Isto porque as regulações impõem baixas densidades em espaços com características biofísicas bastante adequadas, e maiores densidades em áreas já ocupadas com maiores níveis de sensibilidade ambiental, indicando processo de proteção ambiental seletiva.

Tendo como base os trabalhos de Anjos (2008), Barreto, (2008), Ribas (1988), SEMATEC; IEMA; ENGEVIX; IBAMA (1996), e Freitas (2009), identificamos três níveis de sensibilidade ambiental no território estudado. De acordo com os dados levantados sobre as características biofísicas do território, o nível de menor sensibilidade corresponde a um plateau próximo ao divisor de bacias adjacente aos bairros do Lago Sul e Lago Norte, exatamente na área com maior acesso ao Plano Piloto de Brasília. Na Figura 6, abaixo, a mancha laranja corresponde a esta área com menores níveis de sensibilidade ambiental. Trata-se dos sistemas de terra ST-1 e ST-2 definidos em SEMATEC; IEMA; ENGEVIX; IBAMA (1996). Esta é, portanto, a área mais adequada à urbanização de acordo com o quadro natural. A mancha amarela corresponde à área com níveis intermediários de sensibilidade ambiental, denominado sistema de terras ST-3. São espaços menos propícios à urbanização pois possui uma maior susceptibilidade a enchentes, devido a presença de encostas íngremes e proximidade com os corpos d'água. Como vimos, trata-se também de uma área menos adequada em termos socioeconômicos, devido a sua maior distancia ao centro gerador de empregos, o Plano Piloto de Brasília, o que requer maiores gastos com a expansão das redes de infraestrutura. A mancha cinza, o ST-04 e ST-05, corresponde ao espaço menos adequados de todos, pois além de encostas íngremes possuem tipos de solos inadequados, zonas de amortecimento de cheias, aquíferos próximos a superfícies, dentre outros.

Ao sobrepor os dados do censo de 2010 com essa avaliação ambiental detectamos uma concentração populacional na mancha amarela, que não são os espaços mais propícios à urbanização. Por outro lado, a mancha laranja, mais recomendável para urbanização tanto em termos socioeconômicos como em termos ambientais, permanece com níveis de ocupação bem menores. Tal fenômeno pode ser resultado, puro e simplesmente, de retenção especulativa da terra mais valorizada. Entretanto é bastante plausível inferir que o padrão de urbanização de baixa densidade adotado pelas regulações urbanísticas contribuiu para reproduzir o cenário de exclusão urbana, informalidade e degradação ambiental apresentado. Podemos assim afirmar que, no território da APA do São Bartolomeu, o fenômeno das desigualdades ambientais (discutido em Torres, 1997), toma a forma do contraste entre a abundância de terra 
adequada à urbanização com alto grau de ociosidade e a concentração de alta densidade e infraestrutura precária nos espaços menos adequados à urbanização, que se localizam na periferia das cidades satélites de baixa renda.

É importante esclarecer que este trabalho não questiona a imposição de restrições ambientais em nome da proteção ambiental. O que se questiona aqui é se, de fato, a sensibilidade ambiental realmente existe de forma a justificar a adoção de tais medidas. No caso da primeira mancha urbanizável criada pelo segundo zoneamento em 1996 (linha verde na Figura 5), a resposta a esta questão tende a ser negativa: a maior parte da mancha localiza-se em espaços classificados como ST-1 e ST-2 correspondente à mancha laranja na Figura 6. Se considerado apenas os aspectos fisiográficos do território, a área urbanizável definida em 1997 não justifica as medidas restritivas.

Figura 5: Níveis de sensibilidade ambiental na APA em contraste com o padrão de ocupação

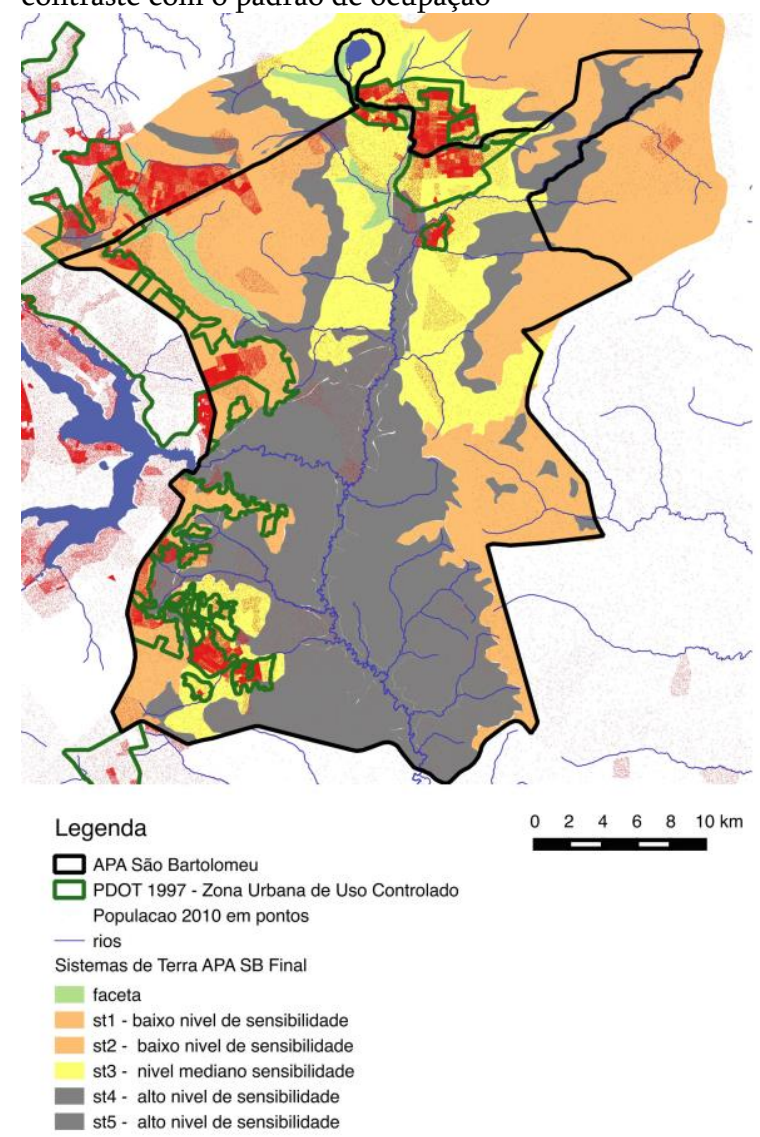

Fonte: Elaboração do autor a partir de IBGE, 2010; Distrito Federal 1997; Distrito Federal 2005; SEMATEC; IEMA; ENGEVIX; IBAMA, 1996;

Esta afirmação é particularmente verdadeira se considerarmos que - no contexto da urbanização do Distrito Federal como um todo - diversas cidades satélites planejadas ${ }^{4}$ com densidades maiores que as adotadas aqui foram instaladas em território com características fisiográficas semelhantes. Isto revela com maior clareza os efeitos socioambientais negativos do modelo de urbanização adotado pela regulação.

É difícil avaliar os efeitos do PDOT 2009 devido a sua recente data de aprovação. Entretanto, como as medidas adotadas fazem parte de uma estratégia semelhante ao plano de 1997, e como não foram implementadas medidas de controle do aumento especulativo dos preços dos terrenos, é factível esperar uma continuidade do fenômeno da exclusão e degradação apresentado aqui.

Considerando que o plano de 2009 empurrou a fronteira de expansão urbana na direção de espaços com maiores níveis de sensibilidade ambiental, sem se certificar que as áreas urbanizáveis existentes haviam sido ocupadas, pode-se afirmar que o plano incentiva um processo de urbanização em saltos, já bastante criticado pela literatura urbana brasileira (i.e. Campos Filho,1999; Costa et al, 2006). O mais relevante do caso analisado, é perceber que discurso ambientalista foi utilizado de forma seletiva no sentido de proteger determinadas áreas em detrimentos de outras com maiores níveis de sensibilidade ambiental. $O$ estudo de caso sugere que uma determinada retórica ambientalista acabou por ajudar a legitimar o aumento da fronteira de expansão urbana sem que os espaços vazios remanescentes dentro da área urbanizável vigente tenham sido efetivamente ocupados.

De fato, no caso da área classificada com Zona de Contenção Urbana no PDOT (que prevê densidades de 15 hab/ha) de 2009, as características biofísicas justificam a adoção de modelos de ocupação restritivos, ao contrário da ZUUC-II. Por que aumentar a fronteira de expansão urbana, num contexto caracterizado pela diminuição do ritmo de crescimento da

\footnotetext{
4 Este é o caso de Riacho Fundo II e Taguatinga.
} 
população do DF?

\section{Considerações Finais}

Este artigo se propôs a verificar o papel da ascensão do objetivo da proteção ambiental no processo de exclusão sócio-espacial, informalidade e degradação apresentado em várias cidades brasileiras, usando como base o caso da APA do Rio São Bartolomeu. A pesquisa realizada nos permite afirmar que o objetivo da proteção ambiental foi utilizado de forma a justificar modelos de ocupação do território restritivos e socialmente excludentes. Ou seja, como resultado de um modelo de planejamento particularmente restritivo à ocupação, que se apropria da proteção ambiental a determinados ecossistemas para favorecer a reserva de terras para o mercado imobiliário de alta renda, há uma concentração de degradação ambiental e vulnerabilidades sociais na periferia. Identificamos ainda uma contradição do discurso presente da regulação urbana/ambiental na medida em que áreas sem grandes implicações ambientais são descritas como frágeis para justificar parâmetros de ocupação elitistas, o que acaba por empurrar a ocupação informal para espaços ambientalmente sensíveis.

A investigação do caso também revelou outros resultados relacionados à questão central. Em primeiro lugar destacamos que o padrão de diferenciação do quadro natural do território mostrou-se relevante para explicar o padrão de segregação sócio-espacial da população urbana. A sobreposição espacial das áreas ambientalmente sensíveis com as áreas mais densamente ocupadas por uma população predominantemente de baixa renda apresentase como um processo socialmente produzido. Mais especificamente, a coincidência entre fragilidade ambiental, informalidade e pobreza, que Davis (2006) discute em inúmeros países periféricos do mundo, apresenta-se como um resultado da ação do Estado de proteção das áreas mais adequadas à urbanização.

Em segundo lugar, destacamos uma relação de complementaridade entre a proteção ambiental e o direito à cidade, muitas vezes difícil de reconhecer nas práticas cotidianas de gestão urbana. Se, por um lado, no caso estudado, a forma com que as preocupações ambientais foram internalizadas pelas regulações urbanas/ambientais não foram capazes de conter velhos processos sociais de exclusão urbana e degradação ambiental, o caso também nos abre possibilidades de alteração deste cenário negativo. Ao relacionar a questão da degradação ambiental com a questão habitacional, podem-se unir dois movimentos sociais que têm até então seguido trajetórias paralelas, e muitas vezes entrado em conflito entre si. Ao adotar uma perspectiva geográfica e um horizonte temporal mais amplo que a maioria dos gestores urbanos, a estudo de caso aqui apresentado ilustra como a solução da degradação ambiental na cidade esta condicionada ao enfrentamento da crise habitacional urbana.

Ao encarar o problema ambiental urbano em toda a sua complexidade, afastando-se da mera oposição à urbanização, o movimento ambientalista pode vir a se tornar um forte aliado no processo de legitimação política dos instrumentos de combate a especulação imobiliária previstos no Estatuto da Cidade. Da mesma forma, políticas preventivas de inclusão urbana, como o IPTU progressivo e ZEIS vazias, podem dar condição para que o poder público exerça um controle efetivo do fenômeno da ocupação informal das áreas frágeis, como as Áreas de Preservação Permanente previstas no Código Florestal Brasileiro.

\section{Agradecimentos}

Esta pesquisa foi conduzida com auxilio da bolsa de doutorado do Conselho Nacional de Desenvolvimento Científico e Tecnológico, CNPq, Brasil, no Programa de Pos-Graduação em Arquitetura e Urbanismo da UNB (entre 2007 e 2009 e posteriormente atualizada). Agradeço a professor Lúcia Cony Faria Cidade, pela sua rigorosa orientação ao longo de toda as fases da pesquisa, desde a formatação inicial do objeto, até a definição do argumento central e pertinência teórica. 
Licensed under a Creative Commons

Attribution International License.

\section{Referências}

ANJOS, R. S. Dinâmica Territorial: Cartografia Monitoramento - Modelagem. Brasília DF: Mapas Editora \& Consultoria, 2008.

ARAUJO, R. P. Z.; CAMPANTE, A. L. G; COSTA, H. S. M. In: Orlando Ales dos Santos, Daniel Todtmann Montandon. (Org.). 1 ed. Rio de Janeiro: Letra Capital Editora, 2011, v., p. 173-217.

BARRETO, R. Identificação das áreas susceptíveis a eventos extremos de chuva no Distrito Federal. Brasília, 2008. (Mestrado em Geografia), Universidade de Brasília.

BATELLA, T. Seminário urbanístico MPDFT. Brasília, 2003. Não publicado.

BRASIL. Decreto № 88.940, de 07 de novembro de 1983. Dispõe sobre a criação das Áreas de Proteção Ambiental das Bacias dos Rios São Bartolomeu e Descoberto, e dá outras providências. Disponível em:

$<$ http://www.ibama.gov.br/siucweb/mostraDocLeg al.php?seq_uc=73\&seq_tp_documento=3\&seq_final iddoc $=7>$. Acesso em: 21 jun. 2009.

BRASIL. Lei No 10.257, de 10 de julho de 2001. Estatuto da Cidade. Disponível em: $<w w w$.planalto.gov.br $>$.

BRASIL. Lei № 9.262, de 12 de janeiro de 1996. Dispõe sobre a administração da Área de Proteção Ambiental (APA) da Bacia do Rio São Bartolomeu, localizada no Distrito Federal, e dá outras providências. Diário Oficial da União, Brasília, 15 jan. 1996.

BRASIL. Ministério da Habitação, Urbanismo e Meio Ambiente. Secretaria Especial de Meio Ambiente. Caracterização e Diretrizes Gerais de Uso da Área de Proteção Ambiental da Bacia do Rio São Bartolomeu. Brasília: SEMA, 1988. 1 mapa. Escala 1:100.000.

BRASIL. Secretaria Especial do Meio Ambiente. Instrução normativa sema/sec/cap/no002/88. Zoneamento da Área de Proteção Ambiental da Bacia do Rio São Bartolomeu (APA do São Bartolomeu). Brasília, 1988.
Cadernos de Arquitetura e Urbanismo | Paranoá 19

CALDERÓN, J. Regularization of Urban Land in Peru. Land Lines: maio 1998, Volume 10, Numero 3. maio, $1998 . \quad$ Disponível em: http://www.lincolninst.edu/pubs/415_Regularizati on-of-Urban-Land-in-Peru. Acesso em: 18/06/2016.

CAMPOS FILHO, C. M. Cidades brasileiras: seu controle ou o caos. São Paulo: Studio Nobel, 1999.

CODEPLAN. Coletânea de informações socioeconômicas: R.A. XXVIII - ITAPOÃ. Brasília, 2006.

CAMPOS FILHO, C. M. Cidades brasileiras: seu controle ou o caos. São Paulo: Studio Nobel, 1999.

COMPANS, R. A cidade contra a favela: a nova ameaça ambiental. In: Revista Brasileira de Estudos Urbanos e Regionais. v. 9, n. 1 (2007).

COSTA, H.S.M. et al. (org.) Novas Periferias Metropolitanas - a expansão metropolitana em Belo Horizonte: dinâmica e especificidade no eixo Sul. Belo Horizonte: C/Arte e Fapemig, 2006.

DAVIS, Mike. Planeta Favela. São Paulo: Boitempo editorial, 2006.

DISTRITO FEDERAL. Lei no 1.149, de 11 de julho de 1996. Dispõe sobre o rezoneamento ambiental da Área de Proteção Ambiental da bacia do rio São Bartolomeu. Diário Oficial do Distrito Federal, Brasília, 12 jul. 1996.

DISTRITO FEDERAL. Lei Complementar no 17, de 28 de janeiro de 1997. Aprova o Plano Diretor de Ordenamento Territorial do Distrito Federal PDOT e dá outras providências. Diário Oficial do Distrito Federal de 29.01.1997. Disponível em: $<$ http://sileg.sga.df.gov.br/default.asp?arquivo=http \%3A//sileg.sga.df.gov.br/legislacao/distrital/leiscom p/LeiComp2001/..\%255CLeiComp1997\%255Clc_17 _97.html>. Acesso em: 21 jun. 2009.

DISTRITO FEDERAL. Lei Complementar no 803, de 25 de abril de 2009. Aprova a revisão do Plano Diretor de Ordenamento Territorial do Distrito Federal - PDOT e dá outras providências. Diário Oficial do Distrito Federal de 27.03.2009. Disponível em:

$<$ http://sileg.sga.df.gov.br/default.asp?arquivo=http 
\%3A//sileg.sga.df.gov.br/legislacao/Distrital/LeisCo mp/LeiComp2009/lc_803_09.htm> Acesso em: 21 jun. 2009.

DISTRITO FEDERAL. CODEPLAN. Sistema de Informações Territoriais e Urbanas - SITURB. Brasília, 2005.

DISTRITO FEDERAL; IPDF. Plano Diretor de Ordenamento Territorial: Documento Técnico. Brasília, 1997.

DISTRITO FEDERAL; SEDUH; SUPAR. Diagnóstico preliminar dos parcelamentos urbanos informais do Distrito Federal. Brasília, jun. 2006. Disponível

em: <http://www.semarh.df.gov.br/sites/100/155/00000 050.pdf>. Acesso em: 16 jun. 2009.

EVANS, Peter, ed. Livable Cities? Urban Struggles for Livelihood and Sustainability. California, USA: University of California Press Ltd. 200223.

FERNANDES, Edésio. Os desafios da regularização fundiária de assentamentos informais consolidados. Entrevista. Revista AU 186, setembro de 2009. Ed. PINI. São Paulo: 2009.

FREITAS, Clarissa F. S. Proteção Ambiental e Direito à Cidade no processo de expansão urbana do Distrito Federal: até que ponto existe um conflito? Brasília, 2009 (Doutorado em Arquitetura e Urbanismo).

FREITAS, Clarissa F. S. GOMES, Viridiana Gabriel. Cap. 4.7 Aspectos Urbanísticos. In Relatório de Impacto de Vizinhança do Parcelamento do Solo ADE São Sebastião. Texto não publicado. 2009.

FREITAS, Clarissa Figueiredo Sampaio. Ilegalidade e degradação em Fortaleza: os riscos do conflito entre a agenda urbana e ambiental brasileira. urbe, Rev. Bras. Gest. Urbana, Curitiba, v. 6, n. 1, p. 109125, Apr. 2014. Available from $<$ http://www.scielo.br/scielo.php?script=sci_arttext \&pid=S2175-

$33692014000100009 \& \operatorname{lng}=\mathrm{en} \& \mathrm{nrm}=\mathrm{i}$ so $>$. access on $30 \quad$ Apr. 2018.

http://dx.doi.org/10.7213/urbe.06.001.AC02

IBGE. Censo Demográfico 2000. AGREGADOS
POR SETORES CENSITÁRIOS DOS RESULTADOS DE UNIVERSO - 2a edição. Rio de Janeiro, [2006]. Disponível

em $\mathrm{ftp}$ //ftp.ibge.gov.br/Censos/Censo_Demografico_20 00/Dados_do_Universo/Agregado_por_Setores_Ce nsitarios Acesso em 02 ago 2009.

IBGE. Censo Demográfico 2010. AGREGADOS POR SETORES CENSITÁRIOS DOS RESULTADOS DE UNIVERSO. Disponível em http://censo2010.ibge.gov.br/.

MARICATO, E. Metrópole periférica, desigualdade social e meio ambiente. In: VIANA, Gilney; SILVA, Marina; DINIZ, Nilo (Org.). O desafio da sustentabilidade: um debate socioambiental no Brasil. São Paulo: Fundação Perseu Abramo, 2001. p. 215-232.

MARTINS, M.L.R. Moradia e mananciais: tensão e diálogo na metrópole. São Paulo: FAUUSP; FAPESP, 2006.

MORETTI, R. S. Normas urbanísticas para a habitação de interesse social- recomendações para elaboração. 2. ed. São Paulo: Instituto de Pesquisas Tecnológicas, 1997. v. 1. 160p.

MUKHIJA, V. \& A. Loukaitou-Sideris, (Eds), The Informal American City: Beyond Taco Trucks and Day Labor, Cambridge, MIT Press, 2014.

RIBAS, O. Critérios e diretrizes de planejamento e desenho urbano para a asa nova norte. Brasília, 1988. (Mestrado em Arquitetura e urbanismo) Universidade de Brasília.

ROLNIK, R. (Org.). Estatuto da Cidade - guia para implementação pelos municípios e cidadãos. 1. ed. Brasília: Câmara dos Deputados, 2001. v. 1. 274p.

SEMATEC; IEMA; ENGEVIX; IBAMA. Revisão e atualização das diretrizes gerais de uso da área de proteção ambiental da bacia do rio São Bartolomeu: relatório final. Brasília, 1996. $4 \mathrm{v}$.

TORRES, H. G. Desigualdade ambiental na cidade de São Paulo. Campinas, 1997. Tese (Doutorado) IFCH; Universidade Estadual de Campinas. 